\title{
Economic Viability Assessment of NASA's Blended Wing Body N3-X Aircraft
}

\author{
C. Goldberg*, D. Nalianda ${ }^{\dagger}$ P. Pilidis ${ }^{\ddagger}$ and R. Singh ${ }^{\S}$ \\ Cranfield University, Bedfordshire, MK43 OAL, United Kingdom
}

\begin{abstract}
Numerous novel aircraft concepts are under development that aim to achieve dramatic increases in efficiency and reductions in emissions in comparison to current aircraft. Research into these concepts typically focuses on performance aspects to establish whether the aircraft will be capable of meeting developmental goals. However, the final goal of such concepts is to progress to viable commercial products. Economic viability assessments are therefore an integral part of the development process to ensure a sustainable industry. The key question to address is whether a high efficiency aircraft concept can translate into an attractive product from an economic perspective.

This research performed an economic viability assessment of NASA's N3-X aircraft, a blended wing body aircraft with a distributed boundary layer ingesting propulsion system. The sensitivity of the aircraft's direct operating cost to changes in acquisition price and maintenance cost was predicted to establish maximum cost margins for the aircraft. In a May 2017 fuel price scenario, the N3-X could be no more than $25 \%$ more expensive than the baseline aircraft to remain economically viable. Introducing a carbon tax or fuel price jump widens the margin for increased costs. Aircraft cost estimates for the aircraft predict an acquisition cost from 11-37\% more expensive than the baseline. In combination with the direct operating cost sensitivity analysis, the N3-X is predicted to need to capture $30 \%$ of the aircraft market up to 2035 .
\end{abstract}

\section{Nomenclature}

$\begin{array}{ll}\text { Acronyms } & \\ B L I & =\text { Boundary layer ingestion } \\ B W B & =\text { Blended wing body } \\ C E R & =\text { Cost-estimating relationship } \\ D O C & =\text { Direct operating cost } \\ I R R & =\text { Internal rate of return } \\ M P C M & =\text { Manufacturing process cost model } \\ P C M & =\text { Parametric cost model } \\ \text { SEE } & =\text { Standard error of estimate } \\ \text { SFC } & =\text { Specific Fuel Consumption } \\ T E R A & =\text { Techno-economic and Environmental Risk Assessment } \\ T R L & =\text { Technology readiness level } \\ \text { Symbols }\end{array}$

\section{Introduction}

The development of new, more efficient technology is an integral part of the growth of the aviation industry. Whilst a modern aircraft is superficially similar to its predecessors, the tools and technologies used in their design have led to dramatic improvements in efficiency in comparison to their predecessors. As with any

\footnotetext{
* Research Assistant, Propulsion Engineering Centre, Cranfield University.

† Lecturer, Propulsion Engineering Centre, Cranfield University.

$\ddagger$ Head of Centre, Propulsion Engineering Centre, Cranfield University.

$\S$ Professor Emeritus Gas Turbine Engineering, Cranfield University.
} 
commercial industry, a core driver behind the development of new technologies is to offer a product that increases profitability. In aviation, this is typically gained through reductions in fuel consumption, a cost that can account for more than a quarter of an aircraft's direct operating cost [1]. However, the global community in the $21^{\text {st }}$ century has become increasingly aware of its impact on the environment. This awareness has added an additional goal to the development of new technology: the mitigation and reduction of industry's impact on the environment. The key aspects of this goal are the reduction of aviation's energy consumption (i.e. fuel use) and the reduction of emissions, especially carbon dioxide, oxides of nitrogen, and noise. The goals of reducing energy consumption lies in line with the typical course of development in aviation to lower fuel consumption and hence reduce fuel cost. However, aviation bodies have targeted dramatic reductions in energy consumption and emissions that cannot be met without the development of revolutionary new technologies [2, 3].

As commercial entities, airlines and manufacturers are naturally profit-oriented. It is therefore inevitable that the decisions made will be influenced by economics, be it operating strategies or the purchase of new assets. In a high fuel price environment, the financial penalties of operating older, less-efficient aircraft are high. The purchase of new aircraft and interest in new technology is therefore relatively lower. In an opposite scenario, the cost of operating older aircraft is less significant as fuel contributes less to the overall operating cost. Older aircraft may therefore be brought out of storage rather than investing in new technology [1]. It is therefore vital that new technologies can be shown to have the potential to provide profitable solutions to manufacturers, owners, and operators and ensure that they are commercial viable.

The development of revolutionary or novel technologies entails a higher degree of risk than the evolutionary development of conventional technology. Novel concepts require the investment of significant time and money to ensure that the technology can move from a low technology readiness level (TRL) preliminary design through to certification and commercial use. The development of new aviation technology can span a timeline that means a new aircraft takes more than a decade to move from concept to a commercial product. Reflecting this, aviation's developmental goals also span long timelines, with NASA's Subsonic fixed wing project settings goals for 2035+ and Flightpath 2050 setting a goal for 2050. Long timelines contribute further uncertainty to the development of new technology, as the environment in which the new technology must operate (in terms of global policy, taxation, economic environment and fuel price) is an unknown. Given the risk and uncertainty of novel technology, a large body of research covering all aspects of each novel technology is necessary. Research at the preliminary stage typically focuses on predicting the performance characteristics of the technology. Given the commercial orientation of the industry, it is vital to ensure that new aircraft concepts remain profitable whilst also meeting established developmental goals.

This research presents the techno-economic analysis of a novel aircraft concept, NASA's N3-X, designed for a 2035 + to achieve $60 \%$ fuel saving versus a 2005 entry-into-service aircraft (the Boeing 777-200LR). The aim of the research was to assess the economic benefits of the N3-X in comparison to the baseline aircraft and to present a framework for predicting the economic viability of novel aircraft concepts.

\section{Case Study Definition}

The present research focuses on a case-study of the NASA N3-X conceptual aircraft, developed by Felder et al $[4,5]$. The N3-X aircraft is designed to reduce fuel/energy consumption by at least $60 \%$ relative to a conventional 2005 entry-into-service aircraft. Following the established performance characteristics of the selected baseline aircraft, mission level goals have been set for the N3-X aircraft in terms of payload and range requirements. The $\mathrm{N} 3-\mathrm{X}$ is therefore ideally required to achieve a mission range of at least $7500 \mathrm{nmi}$ at Mach 0.84 with a full payload (payload mass equal to the aircraft maximum of $53,570 \mathrm{~kg}$ ). In order to achieve the required efficiency improvements, the aircraft makes use of a number of novel technologies in both the airframe and the propulsion system. The aircraft propulsive power is provided by a distributed propulsion system consisting of an array of propulsor fans which ingests the boundary layer of the airframe, along with free stream air. Electrical power for the propulsor fans is produced by a pair of turbojet/turbogenerator type engines through a superconducting system, cooled by liquid hydrogen. The N3-X airframe is a blended wing body planform with main engines assumed to be embedded within the airframe (Figure 1). The embedded engine and propulsor array location provide noise shielding to achieve the required noise targets [6]. Fuel burn and emissions targets are achieved through utilisation of the boundary layer ingesting distributed propulsion system and a blended wing body airframe [5]. 


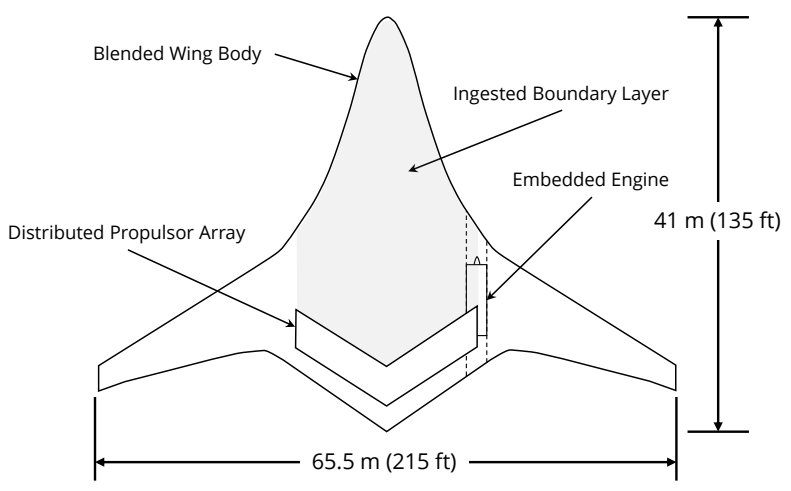

Figure 1: N3-X aircraft diagram

\section{Method}

There are numerous goals when optimising an aircraft design, such as achieving a low fuel consumption, operating empty weight, or cost. However, an optimised aircraft design does not guarantee a profitable solution, as competitors and alternative options may offer a more attractive solution. It is therefore useful to apply tools that can compare performance and economics against these alternatives.

Aircraft costs resulting from performance are relatively easily identified as an extension of performance assessments. However, further costs are contributed as a part two key uncertain costs: the aircraft's acquisition price and value, and its maintenance cost. This complicates the assessment of novel technology from an economic perspective. Cost predictions may be created for aircraft in a number of ways. They can typically be split into two categories; Parametric Cost Models (PCM) and Manufacturing Process Cost Models (MPCM) [7]. These two categories of model attempt the overcome the difficulties of estimating the cost of an engineering project from different perspectives and at different levels of fidelity. Parametric cost models make use of historical data to establish a statistical relationship between variables. In the case of cost estimation, this will be between the cost of the aircraft and the design parameter or parameters found to correlate well with cost. The relationship between the dependent variable cost and its independent variables can be determined using a regression analysis to create a cost estimating relationship (CER). MPCM models support a bottom-up design process, which assess each component and the processes required for its manufacture, building up to an estimation of the total aircraft cost. However, both techniques are difficult to apply to novel or preliminary designs. There is insufficient design detail at the preliminary stage to enable a cost estimate based on manufacturing process, whilst novel aircraft are not typically covered by the historical data used to create parametric cost estimating relationships. This is therefore an aspect that must be addressed when attempting to predict the economic performance of a novel concept. Research by Nalianda et al. developed a sensitivity analysis method which predicts the influence that the two key costs have over an aircraft's direct operating cost [8]. The sensitivity analysis may be used to compare the direct operating cost of a novel aircraft to that of a baseline aircraft to assess whether a novel concept is profitable and provides a good return on investment. Using this form of analysis, the design of a new conceptual aircraft may be assessed from a manufacturers or operators perspective for any fuel cost and/or emissions taxation scenarios. Subsequently, the maximum viable acquisition price and maintenance cost for the aircraft may be predicted. For a given set of novel technologies that are included in the design, a decision may then also be made as to whether the established maximum cost boundaries are achievable. This method circumvents the difficulty of predicting the acquisition or maintenance cost of a novel concept.

\subsection{Performance Modelling}

\section{Boundary Layer Ingestion}

The boundary layer ingesting propulsion system of the N3-X was simulated from an integrated / net propulsive force perspective. Inlet mass flow characteristics were approximated as the mass flow averaged properties for the entire inlet stream for all flow conditions [9]. The propulsor array's performance was otherwise calculated using conventional one-dimensional gas dynamics methods. The propulsors were assumed to have a variable area nozzle [4]. Fan mass flow, efficiency, and pressure ratio at alternative power settings for propulsors in the array were determined from a scaled fan map. 


\section{Turbomachinery}

Engine modelling and simulation was performed using an in-house gas turbine performance assessment tool [10]. Using the tool, a model of the engine can be created from a selection of modules to simulate the engine thermodynamic performance and predict gas properties of the individual gas turbine components. This in turn allows for a detailed simulation of the overall engine performance.

The propulsive power for the baseline aircraft is provided by a pair of twin spool turbofan engines. The performance of the power plants was simulated using public domain data available for the GE90-115B turbofan engine. The performance data with which the engine was simulated and verified included sea level static thrust $(514 \mathrm{kN})$ mass flow $(1641 \mathrm{~kg} / \mathrm{s})$ and bypass ratio at cruise (between 7.1 and 8.9) [11]. The design point of the engine was fixed at a cruise altitude of 35,000 feet and Mach 0.85 .

The main engines of the N3-X are required to provide power for the aircraft propulsor array through a superconducting electrical system. The engines are therefore primarily power producing, although a small amount of core nozzle thrust is produced to counteract the engine drag. Power requirements are defined by the propulsor array, with each of the main engines providing half of the required power, including an assumed transmission loss of $0.2 \%$ [5]. The engines were sized for the aerodynamic design point, with cruise defined at 40,000ft and Mach 0.84 [12]. A number of key engine parameters for the simulated baseline and N3-X engines are listed in Table 2. Further engine design and component efficiency parameters for the N3-X main engines as assumed for this study may be found in the referenced sources $[4,5,12]$.

Table 2: Engine simulation parameters for the baseline aircraft and N3-X main engines

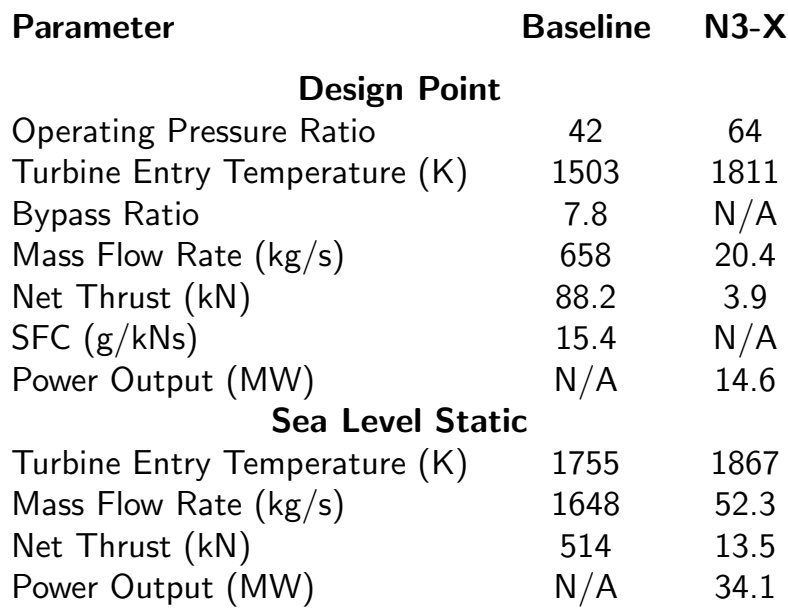

\section{Aircraft Performance Simulation}

Conventional aircraft mission simulation tools are designed to support standard aircraft configurations and propulsion systems. However, there are a limited number of tools available to enable the simulation and integration of the novel propulsion system architecture of the N3-X. Therefore, a custom aircraft performance model was created for this study, to combine conventional aircraft simulation methods with a module to simulate a novel and highly integrated propulsion system [9]. The mission performance model applied a point mass approximation of the aircraft. Block fuel burn was estimated by splitting the aircraft mission into taxi, take-off, climb, cruise, descent, and landing segments. No improvements to air traffic management were assumed for 2035. The aircraft are therefore assumed to cruise at a fixed altitude.

Weights and dimensions for the N3-X were obtained from referenced sources $[4,5,12]$ in combination with a 3-D model of the aircraft available in the public domain [13]. Weights and dimensions for the baseline aircraft were obtained from publicly available sources[14]. Performance obtained from the simulation model of the baseline aircraft was verified against actual payload-range performance information available for the baseline aircraft[14]. The simulated baseline aircraft indicated a maximum payload range of 7,474 nautical miles ( $<1 \%$ error), a maximum fuel range of 9,242 nautical miles ( $<1 \%$ error), and a maximum ferry range of 10,218 nautical miles $(2.7 \%$ error). 


\subsection{Economic Modelling}

The economic performance of a product or project may be represented by identifying the operating cost and revenue produced. Operating cost may be split into two components, direct and indirect [1]. Direct costs can be easily associated with a project, such as materials, labour, or maintenance. Indirect costs are typically more difficult to attribute to a single project, and will include administrative staff salaries and similar miscellaneous costs. Although indirect operating costs must be included in a company-wide assessment, it includes costs which may be distributed over a range of projects. Therefore, direct operating cost is more useful as a point of comparison. The present study is considered from the perspective of an airline operator and assumes the outright purchase and operation of a new aircraft. The direct operating cost is therefore the summation of the following components [1]:

- Fuel

- Emissions taxation

- Maintenance (engine and airframe)

- Insurance

\section{- Depreciation}

- Interest repayment

- Crew salary

Both fuel cost and emissions taxation are related to aircraft performance parameters as determined by an aircraft mission simulation. The emissions taxation component enables the simulation of alternative scenarios and policies, such as carbon taxation. The remaining components are financial rather than performance related and can contribute around three quarters of the overall aircraft operating cost [1]. Assuming the aircraft is purchased through financing - rather than leased - interest on the cost must be repaid over the aircraft life. Depreciation is not a direct outflow of money, however, it represents the decrease in value of the aircraft over its life. The useful life and residual value of an aircraft at the end of its life depends on operator policy [15]. For the present work, residual aircraft value was assumed to be $10 \%$ of the initial value over a 20 -year useful life. Insurance cost depends on the risk of operation, and was assumed to be $0.5 \%$ of the aircraft value per year for the present research [1].

Investment cost analyses are often performed to assist in project and investment decisions. Amongst some of the methods available the application of the concept of Net Present Value calculation (NPV) is quite prevalent. NPV is an economic valuation concept that accounts for the fact that incomes or expenditures in the future have less impact than their value at present. Further, a project's profit and loss are weighted by making use of a discount factor. Often the discount factor applied is the interest rate, or the weighted average cost of capital (WACC), a value which accounts for the weighting of costs a company may attribute to debt and equity. The discount factor represents the return on investment that would be required to exceed the return achieved by investing the money elsewhere. When comparing a selection of project investments, the one offering the highest NPV is the one most likely to be selected. Alternatively, the Internal Rate of Return (IRR) may be calculated. This value is the rate for which the project NPV breaks even, i.e. expenditures exactly cancel out revenue. A project should ideally exceed the minimum required return rate to be considered a suitable investment. This minimum is represented by the WACC, which is $7-8 \%$ for the airline industry [16]. In the present work, the NPV analysis was made in terms of the difference in direct operating cost between the baseline aircraft and N3-X, as revenues were assumed to be equal. The project IRR was subsequently calculated based on this DOC difference, with a NPV formulation as follows [8]:

$$
\Delta X=\sum_{n=1}^{\text {life }} \frac{\Delta \mathrm{DOC}}{(1+\mathrm{IRR})^{n}}
$$

In this formulation, $\Delta X$ is equal to the difference in aircraft purchase cost), $\triangle \mathrm{DOC}$ is the difference in direct operating cost, and IRR is the real rate of return for which the project NPV is equal to zero. The term $n$ represents the years in the aircraft's economic life, up to the assumed maximum of 20 years. Direct operating cost was calculated as cost per flight. Fuel cost and emissions cost were calculated on a cost per flight basis from the performance analysis. Insurance, depreciation and interest repayments were calculated as costs per year and were subsequently distributed over the number of missions flown per year. Maintenance cost and crew salary were per flight hour terms scaled to the length of the flight. A maintenance severity curve was included to scale maintenance cost per flight hour to the flight length and flights per year. Flight cycles per year were scaled based on flight length and reference data on the B777-200LR [17].

The effect of inflation can be included in the calculation by either modifying the cash flow or the rate of return. In the first case, the cash flow is inflated using the current inflation rate and discounted using a 
money or nominal rate of return. In the second case, the cash flow is left in terms of the real cash flow value at the project start, and the inflation correction applies to the discount factor as a real rate of return [18]. Including inflation becomes increasingly relevant in the case of projects with long life cycles. In the present study, the real cash flow and rate of return will be used. Therefore, the inflation rate is accounted for within the rate of return term, whilst the cash flow values are in terms of the value of money at the start of the project.

The technologies in the N3-X concept create a unique challenge for an economic assessment of the aircraft, as they are not currently in commercial use and incorporate many novel technology concepts. As previously described, the sensitivity analysis method considers the sensitivity of direct operating cost to changes in acquisition and maintenance cost. This has been found to be particularly useful as it enables identifying a range of viable costs at the preliminary design stage. The change in direct operating cost was then estimated by scaling the two uncertain costs as a percentage increase in comparison to the baseline aircraft[8]. Figure 2 presents a sample of the sensitivity analysis, consisting of three distinct regions marked by the two indicated trend lines.

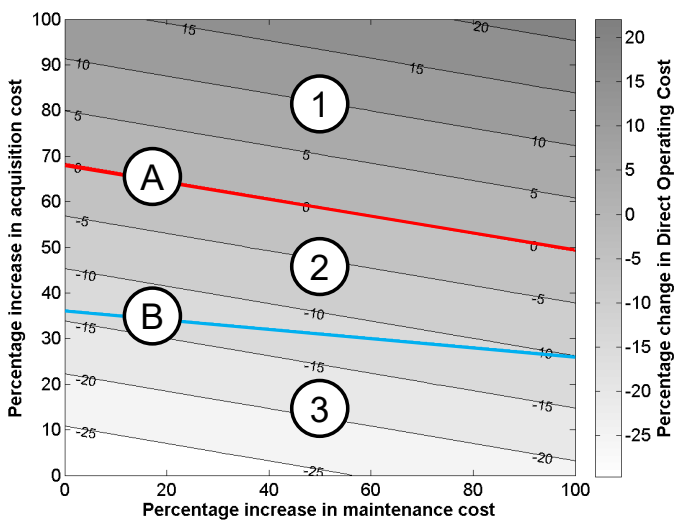

(1) Non-profitable (2) Profitable, inadequate IRR

(3) Profitable, suitable IRR (good return on investment)

(A) No change in DOC

(B) $I R R=W A C C$

Figure 2: Example output from the economic sensitivity analysis.

\subsection{Cost Estimation}

\section{Airframe}

Both manufacturing process and parametric cost models are not ideal for predicting the cost of a novel aircraft. However, PCM type relationships are better suited to an aircraft at the preliminary design stage, as the details necessary for a MPCM cost estimate are unlikely to be available. Predicting the acquisition cost of novel aircraft at the preliminary design stage is challenging without historical data on which to base estimates. However, it is nevertheless possible to use conventional cost estimating relationships to obtain an initial prediction of cost. Given the difficulty of predicting the cost of novel technology, any cost estimate comes with a degree of uncertainty that can be represented by a confidence interval. This leads to a region of likely cost, as opposed to a single, fixed cost estimate. This may then be combined with the sensitivity analysis of the previous section to identify whether the cost estimate coincides with the viable region (region marked as '3' in Figure 2). Aircraft manufacturers will have well developed models for predicting the cost of a new project and setting a list price for the aircraft. The publicly available parametric models rely on older data to develop trends, and will therefore introduce a large measure of uncertainty into the cost prediction for a novel conceptual aircraft. To counterbalance the estimate uncertainty, it was important to select cost models which include factors that may be used to adjust for novel aircraft concepts. Two publicly models were selected as models with this form of support:

- Rand Corporation (Resetar et al, 1991 [19] with updates from Younossi et al, 2001 [20])

- Roskam, 1990 [21]

Both models build up the cost of an aircraft from several subgroups, comprising of the requirements for the development program, the recurring aircraft manufacture cost, and the cost of other assorted components (e.g. aircraft interiors and engines). The relationships rely primarily on the aircraft's operating empty weight 


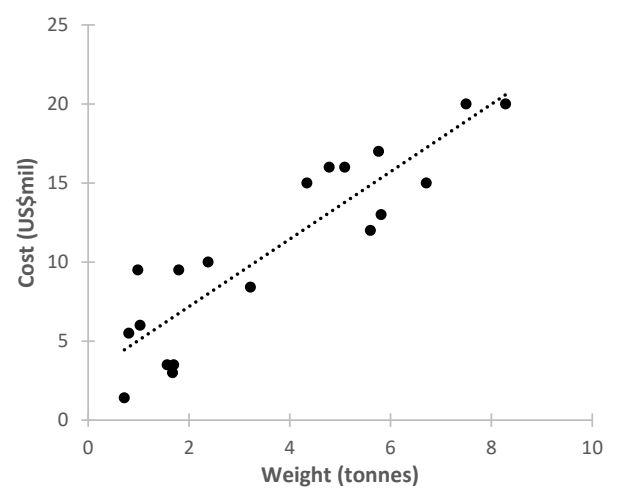

(a) Weight

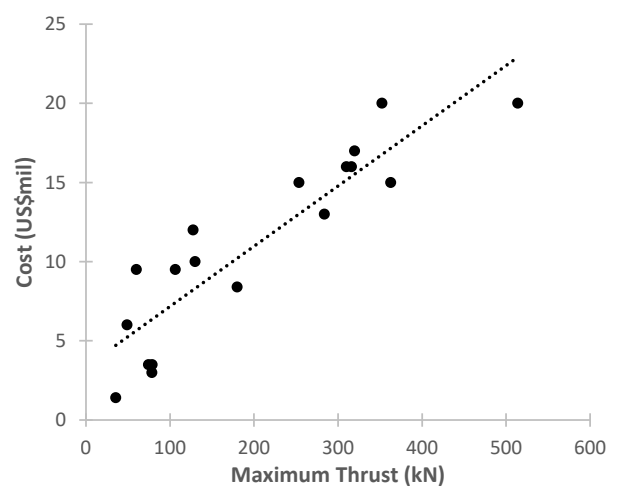

(b) Maximum thrust

Figure 3: Correlation of engine weight and thrust with cost

and speeds as variables, and must be scaled to the current value of money using the rate of inflation. The model by Rester et al and the updates provided by Younossi et al incorporate material factors that may be used to correct for the use of novel materials in an aircraft. It may be assumed that the N3-X will use a large proportion of composites in its construction. In the absence of a detailed breakdown of material type, it will be assumed that it uses the same proportion of composites and metals as the Boeing 787 [22]. The models also require the number of aircraft in the first lot to be defined. It will be assumed that this first lot is covered by aircraft sales prior to the aircraft's entry into service. This is equal to 154 aircraft for the B777 series [23] and will be maintained for the N3-X. The first lot assumption enables the use of a learning curve to each element of the cost estimate. This learning curve means that the manufacturing cost of an aircraft reduces through the aircraft's life as experience is gained. The first aircraft unit is therefore significantly more expensive to manufacture than later units. This cost is averaged out over the number of aircraft in the first produce an average unit cost. Roskam's models follow a similar cost estimation procedure to the Rand Corporation models. Although no material cost factors are presented, the model includes an aircraft difficulty factor that may be used to adjust for novel or new aircraft.

The cost estimates produced by the two selected models were validated against the actual quoted cost for the baseline aircraft: $\$ 320.7 \mathrm{mil}$ for 2017 [24]. The two models produce a reasonable estimate of the aircraft cost with an average error of approximately $4 \%$ (Table 3 ). However, it should be noted that the cost estimate does not include a price increase to ensure a profit margin. It is instead assumed that no profit made until the development program is paid off, i.e. that the list price is the breakeven price.

Table 3: Aircraft unit cost estimates for the baseline aircraft (2017 US\$mil)

\begin{tabular}{lcc} 
& Price & Error \\
\hline Actual List Price & $\$ 320.7$ & - \\
Roskam & $\$ 337.7$ & $5.3 \%$ \\
RAND & $\$ 329.2$ & $2.6 \%$
\end{tabular}

\section{Engine}

Cost estimating relationships for aircraft engines typically rely on thrust as the primary variable. This variable is suitable for conventional engines which are primarily thrust producing. However, it is less useful for the N3-X's engines which are predominantly power-producing engines. To compensate, an 'equivalent' thrustproducing engine may be used. This equivalent engine would have the same design parameters as the baseline N3-X engine, however, the auxiliary power requirement is $0 \mathrm{MW}$. All the engine useful work would therefore go towards producing thrust rather than power. This equivalent engine may then be used to estimate the cost of the baseline engine using cost-estimating relationships that are reliant on thrust. Alternatively, another useful variable is the engine's weight, which correlates reasonably well with cost (Figure 3).

As with the airframe costs, a number of models and relationships were selected for estimating the engine cost:

- Weight and thrust liner regression fits 
- Younossi et al [25]

- Birkler et al [26]

For relationships requiring thrust as a variable, the equivalent engine was used, producing a maximum of approximately $52 \mathrm{kN}$ of thrust at sea level static conditions. As the engine is a turbojet, the thrust produced is lower than that produced by the baseline engines at sea level static conditions. The weight correlation to cost makes use of in-house tools for the estimation of gas turbine weight to obtain a preliminary weight estimate for the N3-X engines.

As with the airframe cost, the cost estimates produced by the two selected models were compared against available information for the cost of the baseline engines; $\$ 22$ mil for 2017 [27]. The average error for the models is approximately $2.5 \%$ (Table 4). However, the relatively larger error of the estimate from the models by Younossi et al suggests it should be excluded from the cost estimating process. The cost of an engine as an individual product is less certain than that of the aircraft, as an engine will typically be bought in combination with an aircraft. However, the models provide a useful estimate for costs at the preliminary design stage.

Table 4: Engine unit cost estimates for the baseline engines

\begin{tabular}{lcc} 
& Price (2017 US\$mil) & Error \\
\hline Price & $\$ 22$ & - \\
Birkler & $\$ 22.7$ & $3.2 \%$ \\
Younossi & $\$ 19.4$ & $-11.9 \%$ \\
Weight Fit & $\$ 20.8$ & $-5.4 \%$ \\
Thrust Fit & $\$ 22.9$ & $4.2 \%$
\end{tabular}

\section{Other Components}

Whilst there are established methods for predicting the cost of engines and airframes, the availability of models for estimating the cost of the remaining components is limited. This is particularly the case for the superconducting electrical system, as superconducting components have not yet been adopted by the aviation industry. Instead, a correlation will be used linking weights estimates for the superconducting motors and generators to cost. The weight of the superconducting motors and generators was predicted using a correlation of shaft power to weight [4].

There is similar difficulty for estimating the price of a propulsor, as turbomachinery preliminary cost estimates focus on the cost of the engine as unit. Instead, a cost estimating relationship provided by Roskam correlating shaft power to the cost of propellers was used [21].

Using such methods does lead to a degree of uncertainty in the cost estimate. However, the cost of the superconducting systems and array is minimal compared to the total cost of the airframe and main engines (2-3\% of the total cost for the N3-X). It has therefore been assumed that the uncertainty in the cost of the superconducting systems and array can be accounted for within the uncertainty of the airframe cost.

\section{Uncertainty}

As has been identified, the cost-estimating relationships are reliant on fits to historical data, leading to inherent uncertainty in the estimates they produce. Estimates are more reliable in the case of aircraft that fit roughly within the period or aircraft design type covered by the database. However, the cost-estimating relationships are less reliable when applied to novel aircraft. It is therefore useful to include the confidence interval when quoting the estimated cost. This confidence interval may be produced from the standard error of the estimate, (SEE, analogous to the standard deviation). Assuming a normal distribution, there is a $95.2 \%$ certainty that the actual list price will lie within \pm two standard deviations of the estimated value. For the purposes of this research, a $50 \%$ confidence interval will be used, i.e. there is a $50 \%$ certainty that the actual price will lie within \pm 0.675 times the standard deviation.

Of the models used, the one provided by Roskam does not make the standard error of estimate for the cost estimating relationships available. Confidence intervals may be created for the remaining method. The standard error for the aircraft cost estimate may be expected to be of the order of $\pm \$ 100$ million. It is possible that an aircraft development project may be lower cost than expected by the initial estimate. However, given that the estimate is being applied to a novel aircraft, there is a higher possibility of costs being greater than expected. This suggests that a distribution which favours values higher than the mean may be more suitable. However, a normal distribution has been maintained for the present research. 
It is challenging to make a firm conclusion on cost given the uncertainty inherent in estimating the cost of a novel or far-future aircraft, and the wide confidence interval. The cost estimates that are produced by the previously mentioned methods can therefore be combined with the sensitivity analysis of Section 3 . By combining the two analyses, it is possible to identify whether the cost (including the confidence interval) coincides with the viable cost margin predicted by the cost sensitivity analysis.

Further development of cost estimates for novel aircraft technology would reduce the cost uncertainty, resulting in a smaller region covered within the $50 \%$ certainty bounds. This form of development follows further research in the aircraft, where cost estimates may become more accurate as a concept moves out of the preliminary phase. In parallel, it is also useful to identify those aspects of the design with the greatest impact on cost and assess whether the benefits offered outweigh the cost.

\section{Results}

\subsection{Direct operating cost comparison}

The N3-X is designed to achieve a $60 \%$ fuel saving in comparison to the baseline aircraft, leading to a large saving in fuel cost. However, the overall direct operating cost also includes the remaining cost factors listed in Section 3. The overall saving in the direct operating cost per flight cycle is therefore dependent on the remaining cost components. In the present analysis, fuel cost is equal to a May 2017 value of $\$ 456.4 / \mathrm{mt}$ ( $\$ 57.9 / \mathrm{bbl}$, IATA Fuel Price Monitor [28]). For the modelled baseline aircraft, fuel contributes between approximately $20 \%$ and $36 \%$ to the total direct operating cost for missions between 750 and 7500 nautical miles (Figure 4a). Although fuel contributes a reasonably large percentage to the total direct operating cost of the modelled baseline aircraft, a reduction in fuel consumption will lead to a relatively smaller reduction in the direct operating cost. The N3-X is designed to achieve $60 \%$ fuel saving verses the baseline aircraft. Taking this value, the direct operating cost saving possible for the design 7500 nautical mile mission is approximately $23 \%$ (Figure 5). Fuel consumption for the shorter range missions is lower, and hence contributes a smaller percentage to the total operating cost. There is therefore less potential for a saving in direct operating cost, even with a large saving in fuel consumption. Nevertheless, there is the potential for a $10 \%$ direct operating cost saving for the shortest simulated mission of 750 nautical miles. This presents a challenge for the N3-X, as there is a relatively low margin for operating cost increases before the costs of the aircraft outweigh fuel consumption benefits.

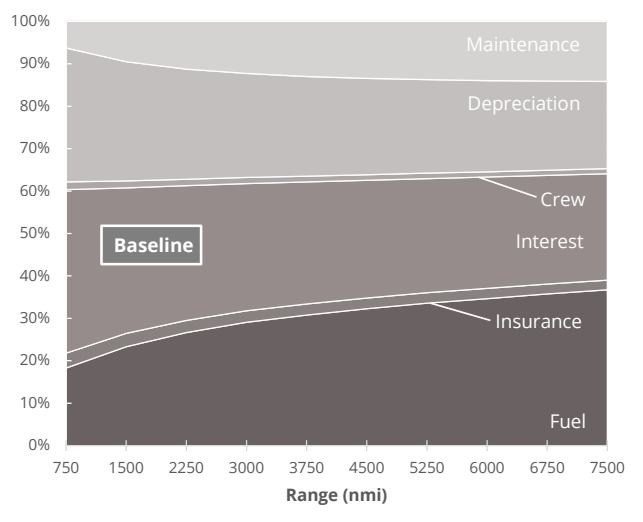

(a) Baseline

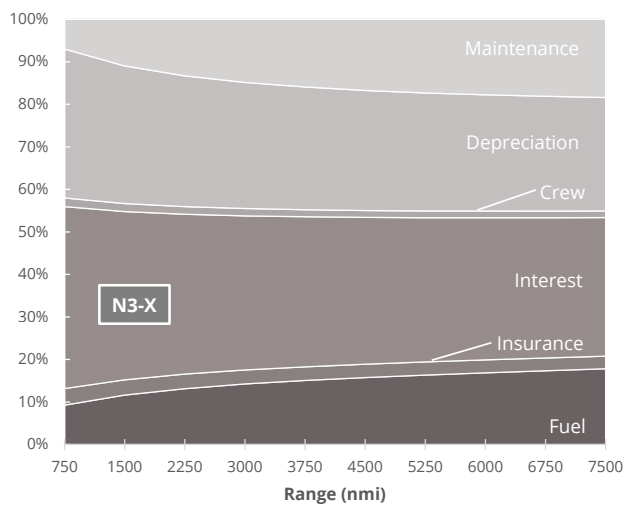

(b) N3-X

Figure 4: Percentage contribution of direct operating cost components to total direct operating cost as a function of mission length

The breakdown of cost components highlights a key aspect of the direct operating cost of a high efficiency aircraft. If the acquisition price and maintenance cost for the N3-X is assumed to be the same as that of the baseline aircraft, fuel contributes to approximately $10 \%-18 \%$ of the overall operating cost (Figure $4 \mathrm{~b}$ ). The dominant factor of the aircraft's operating cost is therefore ownership costs (especially interest repayment on an expensive aircraft). It may be reasonably safely assumed that the acquisition price and maintenance cost of the N3-X would be higher than that of the baseline aircraft. Fuel price would therefore contribute an even lower percentage to the overall operating cost, reducing the direct operating cost benefits attained by the aircraft. This therefore suggests that the driving force behind new developments may seek to achieve 


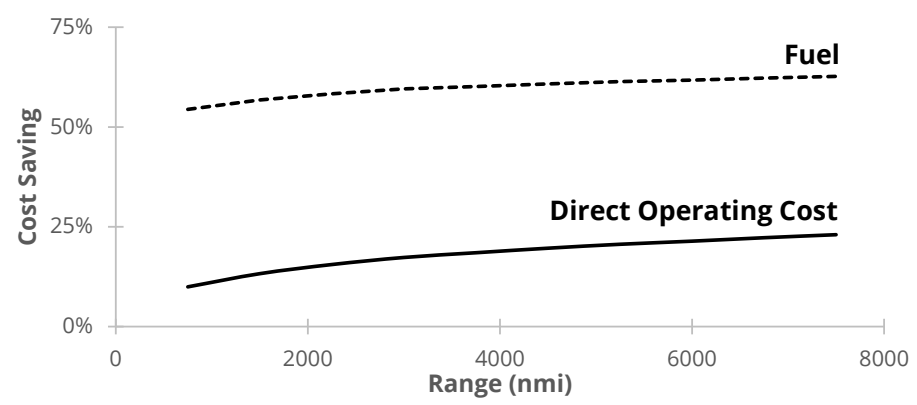

Figure 5: Direct operating and fuel cost saving versus the baseline aircraft

reductions in acquisition price and maintenance cost components, rather than fuel consumption, as these costs become dominant.

\subsection{N3-X Acquisition Price Estimate}

Cost estimates for the N3-X were made using the previously identified models. The Rand model by Resetar et al and Younossi et al produces a significantly lower cost estimate than Roskam's model (Table 5). Assuming that the aircraft would not cost less than the mean cost estimate, the N3-X could be anywhere between $11 \%$ and $37 \%$ more expensive than the baseline aircraft (Rand models with $50 \%$ confidence interval). Roskam's model predicts a higher cost at 39\% greater than the baseline. It should be highlighted that, following the Rand model methods, this cost estimate assumes a 'first lot' of aircraft equal to that assumed for the baseline aircraft: 154 aircraft. The Rand model estimate was selected for the further analyses, as it enables the use of confidence intervals.

The airframe cost estimate also includes the cost estimates for the propulsion system (engines, array, and superconducting electrical system). As the engine is a turbojet/turboshaft rather than a turbofan, it is smaller and lighter than the baseline engine. The cost estimates for the N3-X main engine are therefore lower than that of the baseline engine. The costs of the remaining propulsion system components may also be estimated based on the array size and power requirements for the 15-fan array. These estimates have been taken as preliminary values only, given the assumptions used in producing them. The total cost estimate for the combined propulsion system is approximately $\$ 38.9$ mil, comparable to the $\$ 40.4$ mil for the baseline aircraft. Given the uncertainty in the cost estimate, the final value should be integrated within the cost sensitivity analysis to determine whether the estimated cost range lies within the feasible cost range for the N3-X.

Table 5: Aircraft unit cost estimates for the N3-X (2017 US\$mil)

\begin{tabular}{lccc} 
& Price & $\%$ Difference & SEE \\
\hline Baseline List Price & $\$ 320.7$ & - & - \\
Roskam & $\$ 446.5$ & $39.2 \%$ & - \\
RAND & $\$ 356.2$ & $11.1 \%$ & $\pm \$ 126.6$
\end{tabular}

Table 6: Engine unit cost estimates for the N3-X (2017 US\$mil)

\begin{tabular}{lcc} 
& Price & SEE \\
\hline Birkler & $\$ 5.46$ & $\pm \$ 1.50$ \\
Weight Fit & $\$ 6.12$ & $\pm \$ 2.63$ \\
Thrust Fit & $\$ 5.34$ & $\pm \$ 2.62$
\end{tabular}

\subsection{Sensitivity Analysis}

With the cost of the baseline aircraft as the starting point, the direct operating cost of the N3-X was estimated with acquisition price and maintenance cost increases between $0 \%$ and $100 \%$ of the baseline values. Assuming a maintenance cost per flight hour equal to the baseline aircraft, the maximum feasible acquisition price for the N3-X to achieve a reasonable rate of return would be approximately $25 \%$. This value drops to approximately 


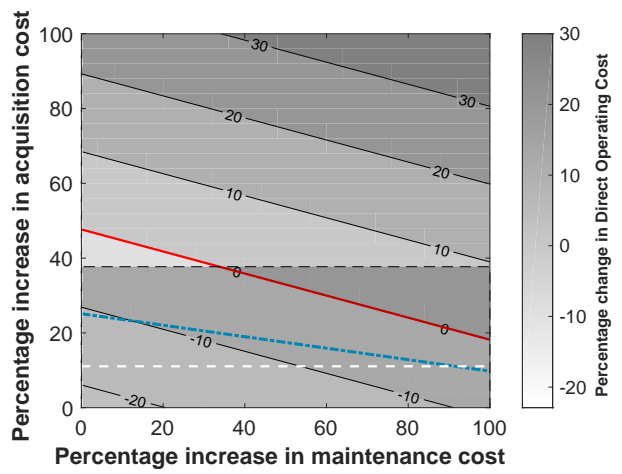

(a) $7500 \mathrm{nmi}$

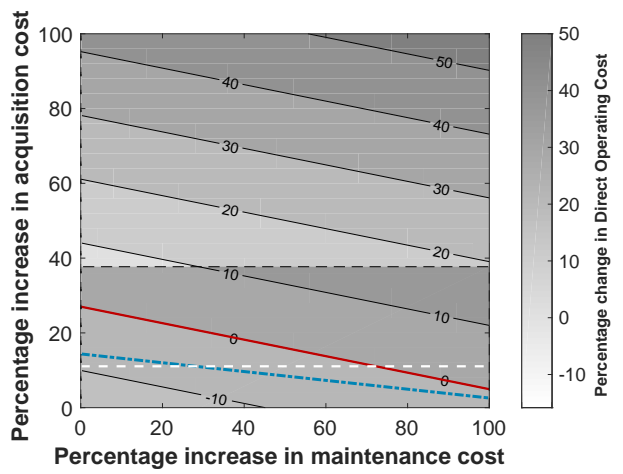

(b) $2500 \mathrm{nmi}$

Figure 6: Direct operating cost sensitivity analysis for the N3-X (including 50\% certainty bounds for acquisition price)

$10 \%$ were the aircraft's maintenance cost to be twice that of the baseline (Figure 6a). Whilst the mean falls reasonably well within this margin, the upper bound of the cost estimate lies almost completely outside the viable cost margins, and would result in an aircraft that was more expensive to operate than the baseline aircraft. The cost margins reduce further if the aircraft is assumed to be used for shorter range missions, which further reduces the region where the cost estimate and viable cost regions coincide (Figure 6b).

There are a number of potential options to adjust the distribution of costs and create a more favourable economic environment for a novel aircraft. Three potential scenarios have been considered in the present research. As has previously been identified $[1,29]$, low fuel costs reduce the incentive for operators to invest in new, more efficient aircraft. Conversely, a higher fuel price increases the penalties of operating older aircraft. In terms of the direct operating cost breakdown of Figure 4, a higher fuel price increases the percentage contribution of fuel to the overall direct operating cost and hence increases the direct operating cost benefit possible through the $60 \%$ fuel saving offered by the N3-X. The N3-X is targeted for a $2035+$ entry into service, and given the unpredictability of fuel price, the cost of kerosene in 20 years is an unknown. Historically, the price of kerosene has been subject to sudden and large changes, in sync with changes in oil price. Fuel prices in the 2011 to 2014 were significantly greater than the fuel price considered in the current research.

Fuel price in May 2012 (5-year interval) was approximately twice the price of May 2017 [28]. This high fuel price proves beneficial to the N3-X, as fuel now contributes $30-50 \%$ of the total direct operating cost of the baseline aircraft. The $60 \%$ fuel saving of the N3-X therefore leads to a direct operating cost saving of up to $30 \%$. This relatively larger saving in direct operating cost significantly widens the margins for increases in cost and hence increases the aircraft's economic viability (Figure 7a).

Alternatively, an emissions taxation scenario could be considered, where a carbon tax is introduced for aviation emissions. Predictions for the price of $\mathrm{CO}_{2}$ emissions in 2035 provide an estimate of between $\$ 30$ and $\$ 73$ per short ton [30]. As with the fuel price scenario, emissions taxation penalises the use of less efficient aircraft and would encourage investment in more efficient options. The cost of emissions adds a further element to the aircraft's direct operating cost and would, for $\mathrm{CO}_{2}$ emissions, increase in proportion with fuel consumption. Taking an emissions taxation scenario of $\$ 30$ per short ton $\mathrm{CO}_{2}\left(\$ 27 / \mathrm{mt} \mathrm{CO}_{2}\right)$, margins for increases in acquisition price and maintenance cost increase in comparison to the baseline scenario. The margins do not cover the upper limit of $50 \%$ confidence interval, however, assuming a cost equal to the mean estimate, maintenance cost could more than double whilst still providing a reasonable return on investment.

A final alternative scenario is a change in interest rate for the aircraft purchase, as interest repayment for an expensive aircraft covers a large percentage of the direct operating cost. The baseline scenario considered an interest rate of $5.5 \%$, however interest rates may vary year on year. Changing the interest rate works primarily to increase the margins for which the aircraft is more profitable than the baseline (Figure 7c). It should also be noted that the analysis assumes aircraft are full financed through debt, however, alternative financing sources may be considered, such as part payments in cash. Financing the aircraft purchase through other sources or a drop in interest rate reduces the yearly interest repayment and hence reduces direct operating cost. With a lower contribution from interest repayments, savings in fuel consumption can lead to a larger percentage reduction in direct operating cost.

Whilst the current research has not considered an aircraft lease scenario, the prevalence of leasing as an aspect of aircraft operation and ownership highlights its importance. It is also important to highlight that different operators will assign different values to the economic life and residual value of the aircraft, which 


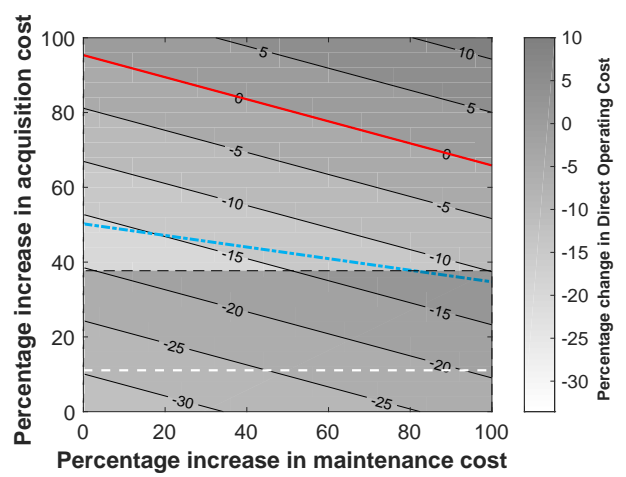

(a) Kerosene $\$ 912.8 / \mathrm{mt}(2012)$

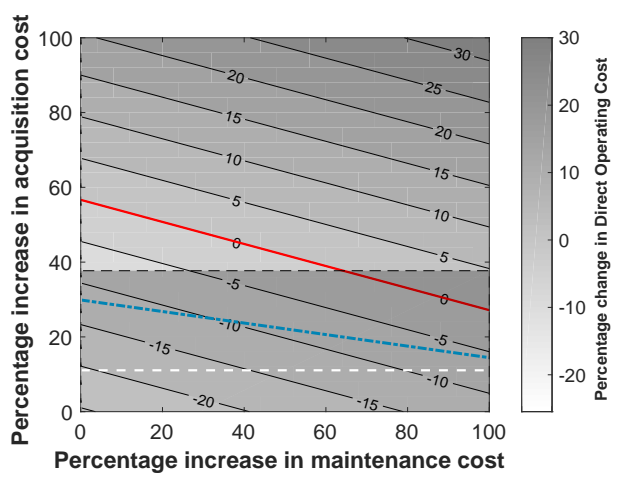

(b) $\$ 30$ per short ton $\mathrm{CO}_{2}$

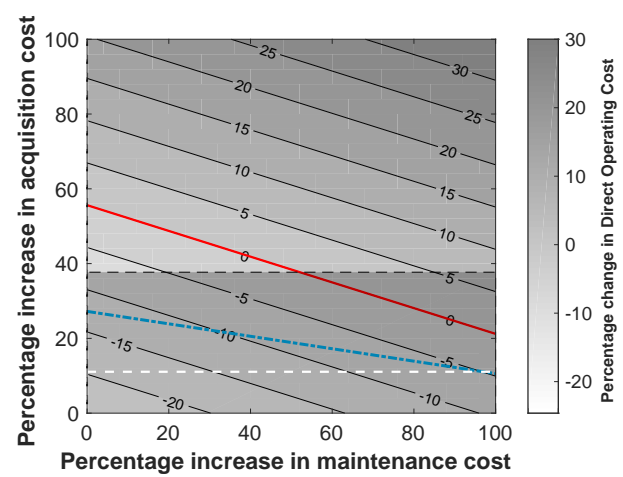

(c) $4 \%$ interest rate

Figure 7: Direct operating cost sensitivity analysis for the N3-X in alternative scenarios for a 7500 nmi mission (including $50 \%$ certainty bounds for acquisition price)

will similarly influence the calculated direct operating cost. The values selected for this research are typical values ( $10 \%$ residual value after a 20 -year life), however, the exact values are operator- and aircraft-specific [31].

\subsection{Aircraft Market}

The previous analyses have assumed that 154 aircraft are produced in the first lot. The more aircraft that are produced and sold, the faster the cost of the aircraft development program may be paid off. In addition, learning curves for aircraft production mean that the cost to produce the aircraft reduces as more aircraft are manufactured. The aircraft's price point (as predicted by the cost estimation model) therefore depends on the number of aircraft in the first lot. The cost estimation methodology may be combined with the viable acquisition cost margin established in the previous section to determine how many aircraft may be required to meet this cost target. For each number of aircraft, the cost estimating relationships may be used to estimate the break-even price, i.e. the list price which would exactly pay off the development program plus the manufacturing cost per aircraft. Finally, it is important to establish whether the aircraft market could support the number of aircraft.

Given the assumptions used in creating the cost estimate, the number of aircraft to break even for an aircraft list price equal to the baseline would be approximately 200 (Figure 8). However, the standard error of the estimate is relatively large compared to lower aircraft numbers, leading to wider range for the potential number of breakeven aircraft. Figure 6a establishes a maximum increase in acquisition price for the N3-X to remain a viable economic product between $10 \%-25 \%$ (for an aircraft used on a $7500 \mathrm{nmi}$ mission). This leads to a prediction of between 120 and 160 aircraft to break even, depending on the aircraft's maintenance cost per flight hour. Taking a cost estimate at the upper limit of the confidence interval, the between 190 and 260 aircraft would be required to break even.

The uncertainty in Figure 8 reflects the real-world case where cost overruns during the development program or a higher than expected manufacturing cost would necessitate the sale of more aircraft to recover costs. Or conversely, for a fixed number of production aircraft, cost overruns would necessitate a higher sale price to break even. 


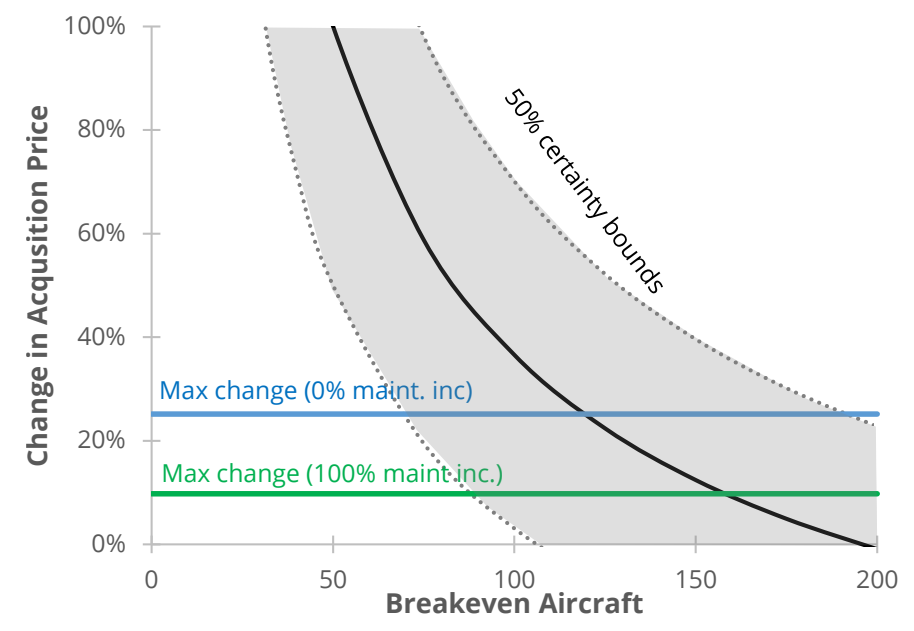

Figure 8: Change in acquisition price versus the baseline as a function of number of aircraft in the first lot (maximum viable acquisition price increase marked for May 2017 fuel scenario)

The remaining question is whether demand in the aircraft market up to 2035 could support in the region 160 new aircraft. Boeing predict that there will be a demand for 530 new large widebody aircraft between 2016 and 2036 [32]. This suggests that the N3-X would need to capture in the region of 30\% of the aircraft market up to 2035 to break even. This estimate is reliant on the modelling assumptions, with the exact value dependent on the economic conditions and the cost estimating methodology. The estimate nevertheless suggests that the N3-X could feasibly be economically viable, assuming costs lie relatively close to the mean estimates. However, if costs were to lie at the upper limit of the $50 \%$ confidence interval, just under $50 \%$ of the new aircraft market would need to be captured by the N3-X (assuming the current economic scenario).

Introducing the economic scenarios of the previous section, such as a higher fuel price or emissions taxation, increases the margin for an increase in acquisition price. This leads to a lower number of aircraft to break even, and hence a lower market capture requirement. For the emissions taxation scenario presented in Figure $7 \mathrm{~b}$, 110-145 aircraft would be required to break even. This reflects conclusions drawn in the previous conclusion, where scenarios that penalise less efficient aircraft will incentivise the purchase and production of more efficient and novel aircraft.

\section{Conclusions}

The research has presented a framework for the assessment of the economic viability of an aircraft from an economic perspective. The framework has made use of a combination of custom models to assess the performance and direct operating cost of the aircraft and publicly available tools for estimating the acquisition price of aircraft at the preliminary design stage. The methodology enables an overview of the influence that efficiency benefits have over the overall direct operating cost of an aircraft and the sensitivity of direct operating cost to acquisition price and maintenance cost. Using this sensitivity analysis, cost margins may be established which define the maximum cost of the aircraft if it is to remain an attractive proposal. In combination with cost-estimating tools, the framework may be used to predict whether the aircraft can achieve a reasonable price point and the number of aircraft sales that might be required to meet the requisite price. Alternative scenarios were also considered to identify the influence of fuel price and emission taxation have over the aircraft's economic viability. The framework was applied to the N3-X, a conceptual aircraft developed by NASA for the subsonic fixed wing project and a 2035+ entry into service.

Given the assumptions of the modelling procedure and a May 2017 scenario, the N3-X could have a list price anywhere up $25 \%$ higher than the baseline (assuming a reasonable maintenance cost) to remain a viable product. This leads to an estimate of 120 aircraft sales, or $30 \%$ of the large widebody aircraft market up to 2035. However, offering the aircraft as an option for high capacity for short haul routes reduces the viable cost for an operator, as a high acquisition price outweighs any fuel consumption benefits.

The fuel price and carbon tax scenarios highlight the influence that economic conditions have over the viability of the aircraft. Scenarios which penalise older, less efficient aircraft will increase the benefits possible for novel and more efficient aircraft. Both manufacturers and operators may therefore be more willing to invest in developing a novel aircraft such as the N3-X. From the operator's perspective, investment in expensive 
novel aircraft may nevertheless reduce direct operating costs, assuming costs stay within acceptable margins. From the manufacturer's perspective, a target price may be established to provide an attractive product offer, leading to an estimate of the number of required aircraft sales. The introduction of carbon tax by regulators would encourage the adoption of novel aircraft. However, significant carbon taxation would negatively impact the profitability and hence sustainability of the industry.

\section{Acknowledgements}

The authors would like to extend their gratitude to NASA for making this work possible under grant number NNX13AI78G. Many thanks go also to staff at Cranfield University for their advice and assistance.

\section{References}

[1] Paul Clark. Buying the Big Jets: fleet planning for airlines. Ashgate Publishing, Ltd., 2007.

[2] Air Transport Action Group. Flightpath. 2013.

[3] Royal Aeronautical Society. Greener by design: Conference report 2014-2015, 2015.

[4] James L Felder, Hyun Dae Kim, and Gerald V Brown. Turboelectric distributed propulsion engine cycle analysis for hybrid wing body aircraft. In 47th AIAA Aerospace Sciences Meeting, Orlando, FL, USA, number AIAA 2009-1132, 2009. doi: 10.2514/6.2009-1132.

[5] James Felder, Gerald Brown, Hyun Kim, and Julio Chu. Turboelectric Distributed Propulsion in a Hybrid Wing Body Aircraft. In 20th International Society for Airbreathing Engines, Gothenburg, Sweden, number ISABE-2011-1340, 2011.

[6] J Berton and W Haller. A noise and Emissions Assessment of the N3-X Transport. In 52nd Aerospace Sciences Meeting, National Harbor, MD, USA, number AIAA 2014-0594, 2014. doi: 10.2514/6.2014-0594.

[7] M Rais-Rohani and EB Dean. Toward manufacturing and cost considerations in multidisciplinary aircraft design. In 37th Structure, Structural Dynamics and Materials Conference, number AIAA 96-1620, 1996.

[8] D K Nalianda, K G Kyprianidis, V Sethi, and R Singh. Techno-economic viability assessments of greener propulsion technology under potential environmental regulatory policy scenarios. Applied Energy, 157: 35-50, 2015.

[9] Chana Goldberg, Devaiah Nalianda, Pericles Pilidis, David MacManus, and James Felder. Installed performance assessment of a boundary layer ingesting distributed propulsion system at design point. In 52nd AIAA/SAE/ASEE Joint Propulsion Conference, number AIAA 2016-4800, 2016.

[10] JR Palmer and V Pachidis. The TURBOMATCH scheme for aero/industrial gas turbine engine design point/off design performance calculation, 1990.

[11] Jane's Aero Engines. Jane's Information Group, 2012.

[12] James L Felder, Hyun Dae Kim, and Gerald V Brown. An Examination of the Effect of Boundary Layer Ingestion on Turboelectric Distributed Propulsion Systems. In 49th AIAA Aerospace Sciences Meeting, Orlando, FL, USA, number AIAA 2011-300, 2011. doi: 10.2514/6.2011-300.

[13] M. Moore. NASA N3-X Concept OpenVSP Model. URL http://hangar.openvsp.org/vspfiles/59. Accessed: June 2016.

[14] Boeing. 777-200/r/-300er/-freighter airplane characteristics for airport planning. URL http://www . boeing.com/assets/pdf/commercial/airports/acaps/777_2lr3er.pdf. Accessed: June 2016.

[15] IATA. Airline disclosure guide: Aircraft acquisition cost and depreciation, 2016.

[16] International Air Transport Association. Airlines finance monitor. URL http://www.iata.org/ publications/economics/Pages/index. aspx. Accessed: June 2016.

[17] Owners \& operators guide: 777-200/-300. Aircraft Commerce, 60:6-30, 2008. 
[18] Stephen Lumby. Investment Appraisal and Financing Decisions. Chapman \& Hall, 1991.

[19] Susan A Resetar, James Curt Rogers, and Ronald W Hess. Advanced airframe structural materials: A primer and cost estimating methodology. Technical Report R-4016-AF, RAND Corportation, 1991.

[20] Obaid Younossi, Michael Kennedy, and John C Graser. Military airframe costs. the effects of advanced materials and manufacturing processes. Technical Report R-4016-AF, RAND Corportation, 2001.

[21] Jan Roskam. Airplane Design Part VIII: Airplane Cost Estimation. Roskam Aviation and Engineering Corporation, 1990.

[22] Justin Hale. Boeing 787 from the ground up. Aero, 24(4):17-23, 2006.

[23] Boeing. B777 Orders and Deliveries, . URL http://active.boeing.com/commercial/orders/ displaystandardreport. $\mathrm{cfm}$ ?cboCurrentModel=777\&optReportType=AllModels\&cboAllModel= 777\&ViewReportF=View+Report. Accessed: May 2017.

[24] Boeing. About Boeing Commercial Airplanes, . URL http://www.boeing.com/company/about-bca/ \#/prices. Accessed: May 2017.

[25] Obaid Younossi, Mark V Arena, Richard M Moore, Mark Lorell, and Joanna Mason. Military jet engine acquisition: Technology basics and cost-estimating methodology. RAND, 2002.

[26] John L Birkler, Jeffrey Bruce Garfinkle, and Kenneth E Marks. Development and production cost estimating relationships for aircraft turbine engines. Technical report, DTIC Document, 1982.

[27] Deagel.com. GE90-115B. URL http://www.deagel.com/Propulsion-Systems/GE90-115B_ a001376002.aspx. Accessed: May 2017.

[28] IATA. Jet Fuel Price Monitor. URL http://www.iata.org/publications/economics/ fuel-monitor/Pages/index. aspx. Accessed: May 2017.

[29] Chana Goldberg, Devaiah Nalianda, and Riti Singh. Techno-economic and environmental risk assessment of a blended wing body with distributed propulsion. In 51st AIAA/SAE/ASEE Joint Propulsion Conference, Orlando, FL, USA, number AIAA 2015-4024, 2015. doi: 10.2514/6.2015-4024.

[30] Patrick Luckow, Elizabeth A. Stanton, Spencer Fields, Bruce Biewald, Sarah Jackson, Jeremy Fisher, and Rachel Wilson. 2015 carbon dioxide price forecast, 2015. Synapse Energy Economics, Inc.

[31] IATA and KPMG. Airline disclosure guide: Aircraft acquisition cost and depreciation, 2016. IATA.

[32] Boeing. Current market outlook 2016-2035, 2016. 
2017-07-12

\section{Economic viability assessment of NASA's blended wing body N3-X aircraft}

Goldberg, Chana

AIAA

pÿGoldberg C, Nalianda D, Pilidis $P$, Singh R, Economic viability assessment of NASA s blended wing body N3-X aircraft, Proceedings of 53rd AIAA/SAE/ASEE Joint Propulsion Conference 2017, AIAA Propulsion and Energy Forum, 10 - 12 July 2017, Atlanta, GA, USA, Paper number AIAA 2017-4604

http://dx.doi.org/10.2514/6.2017-4604

Downloaded from Cranfield Library Services E-Repository 